\title{
Pharmacologic targeting of the P-TEFb complex as a therapeutic strategy for chronic myeloid leukemia
}

Yingjie Qing ${ }^{1 \dagger}$, Xiangyuan Wang ${ }^{1 \dagger}$, Hongzheng Wang ${ }^{1}, \mathrm{Po} \mathrm{Hu}{ }^{1}, \mathrm{Hui} \mathrm{Li}^{1}$, Xiaoxuan $\mathrm{Yu}^{2}$, Mengyuan Zhu', Zhanyu Wang ${ }^{1}$, Yu Zhu ${ }^{3}$, Jingyan Xu ${ }^{4}$, Qinglong Guo ${ }^{1 *}$ and Hui Hui ${ }^{1 *}$ (D)

\begin{abstract}
Background: The positive transcription elongation factor b (P-TEFb) kinase activity is involved in the process of transcription. Cyclin-dependent kinase 9 (CDK9), a core component of P-TEFb, regulates the process of transcription elongation, which is associated with differentiation and apoptosis in many cancer types. Wogonin, a natural CDK9 inhibitor isolated from Scutellaria baicalensis. This study aimed to investigate the involved molecular mechanisms of wogonin on anti- chronic myeloid leukemia (CML) cells.
\end{abstract}

Materials and methods: mRNA and protein levels were analysed by RT-qPCR and western blot. Flow cytometry was used to assess cell differentiation and apoptosis. Cell transfection, immunofluorescence analysis and co-immunoprecipitation (Co-IP) assays were applied to address the potential regulatory mechanism of wogonin. KU-812 cells xenograft NOD/SCID mice model was used to assess and verify the mechanism in vivo.

Results: We reported that the anti-CML effects in K562, KU-812 and primary CML cells induced by wogonin were regulated by P-TEFb complex. We also confirmed the relationship between CDK9 and erythroid differentiation via knockdown the expression of CDK9. For further study the mechanism of erythroid differentiation induced by wogonin, co-IP experiments were used to demonstrate that wogonin increased the binding between GATA-1 and FOG-1 but decreased the binding between GATA-1 and RUNX1, which were depended on P-TEFb. Also, wogonin induced apoptosis and decreased the mRNA and protein levels of MCL-1 in KU-812 cells, which is the downstream of P-TEFb. In vivo studies showed wogonin had good anti-tumor effects in KU-812 xenografts NOD/SCID mice model and decreased the proportion of human $\mathrm{CD}_{4} 5^{+}$cells in spleens of mice. We also verified that wogonin exhibited anti-CML effects through modulating P-TEFb activity in vivo.

Conclusions: Our study indicated a special mechanism involving the regulation of P-TEFb kinase activity in CML cells, providing evidences for further application of wogonin in CML clinical treatment.

Keywords: Wogonin, Cell differentiation, P-TEFb, CDK9, CML

*Correspondence: anticancer_drug@163.com; moyehh@163.com

${ }^{\dagger}$ Yingjie Qing and Xiangyuan Wang have contributed equally.

${ }^{1}$ State Key Laboratory of Natural Medicines, Jiangsu Key Laboratory

of Carcinogenesis and Intervention, China Pharmaceutical University, 24

Tongjiaxiang, Nanjing 210009, People's Republic of China

Full list of author information is available at the end of the article

\section{Background}

CML is a malignant clonal disease that originates in hematopoietic stem cells [1]. Clinically, it is divided into three phases including chronic phase, accelerated phase and blast phase [2]. CML patients commonly arise $\mathrm{t}(9 ; 22)(\mathrm{q} 34 ; 11)$ chromosomal translocation and formation of fusion gene $B C R-A B L 1$, which is otherwise in a credit line to the material. If material is not included in the article's Creative Commons licence and your intended use is not permitted by statutory regulation or exceeds the permitted use, you will need to obtain permission directly from the copyright holder. To view a copy of this licence, visit http://creativecommons.org/licenses/by/4.0/. The Creative Commons Public Domain Dedication waiver (http://creativecommons.org/publicdomain/zero/1.0/) applies to the data made available in this article, unless otherwise stated in a credit line to the data. 
transcribed and translated into BCR-ABL1 protein with tyrosine kinase activity, thereby activating downstream signaling pathways such as PI3K-Akt-mTOR and MAPK, leading to abnormal cell proliferation [1, 3, 4]. Tyrosine kinase inhibitors (TKIs) are currently the preferred drug in clinical CML patients and Imatinib is the first generation of TKIs used for the treatment of CML [5]. However, although TKIs therapy can alleviate the condition of most CML patients, long-term use cannot eliminate the existence of factors such as leukemia stem cells and high price [6, 7]. Therefore, new ideas should be expanded in the development of CML drugs to solve the increasing urgent problems of clinical medication of CML.

Cyclin-dependent kinases (CDKs) are serine/threonine kinases found in yeast, which have the functions of regulating cell cycle and cell transcription $[8,9]$. Cycle CDKs $(\mathrm{CDK} 1,2,4,6)$ mainly play a role in the regulation of cell cycle, while transcriptional CDKs (CDK7-9, 10-13) act on the transcriptional regulation process of cells [10]. Transcription CDKs make RNA Polymerase II (RNA Pol II) carboxyl terminal structure domain (C-Terminal Domain, CTD) phosphorylation, thus promote the initiation and extension of transcription [11]. Inhibition of CDKs mainly affects the accumulation of transcripts with short half-life, such as anti-apoptotic family members' genes $B C L 2, M C L 1$ and XIAP, cell cycle regulating family genes $C C N D 1$ and $C M Y C$, and tumor suppressor genes TP53 [10]. Therefore, transcriptional CDKs is one of the potential targets of tumor therapy.

RNA Pol II is a transcription enzyme, which regulates the messenger RNA and non-coding RNA [12]. RNA pol II activity in the transcription cycle stages is strictly regulated, which makes phosphorylation RNA pol II CTD in dynamic changes and drives transcription from pre-initiation, initiation, extension to termination [13]. RNA transcription is catalyzed by CDK7 and CDK9 in turn. Firstly, CDK7 phosphorylates the serine (ser5) site of CTD of RNA pol II, thus activating RNA pol II and acting as a part of pre-transcriptional initiation complex to promote the initiation of transcription [14]. Subsequently, the serine (ser2) at the second position of CTD of RNA pol II is phosphorylated by CDK9, which promotes the transcription process into the extension stage $[15,16]$. P-TEFb is a kinase complex formed by catalytic subunit CDK9 and regulatory subunit cyclin T1. Under the action of catalytic subunit CDK9, ser2 of CTD of RNA pol II is phosphorylated, which promotes RNA transcription extension [17]. Therefore, P-TEFb plays an important role in the production of cellular mRNA. CDK9 inhibitors inhibit the transcription of downstream genes by reducing the phosphorylation of RNA pol II by inhibiting the formation of P-TEFb [15]. Therefore, targeting CDK9 is an effective tumor therapy strategy [18].

Differentiation induction therapy is a treatment method that uses differentiation inducers to induce malignant tumor cells to transform into mature cells. Normal cells are less affected by differentiation inducers due to their high degree of differentiation. Therefore, compared with chemotherapeutic drugs with poor selectivity and high cytotoxicity, differentiation inducers have lower side effects [19]. Differentiation induction therapy has achieved good effects in the treatment of acute promyelocytic leukemia (APL), which is a model of cell differentiation therapy [20]. However, only retinoic acid (RA) combined with arsenic trioxide has been successful in the treatment of APL. Thus, new differentiation inducers are needed to develop in the treatment of CML.

During the process of hematopoiesis, hematopoietic stem cells (HSC) first differentiate into common myeloid progenitor (CMP), and then CMP differentiate into megakaryocyte erythrocyte progenitor (MEP) and granulocyte macrophage progenitor (GRA) cells. However, MEP can further differentiate into primordial megakaryocytes and erythrocytes, and then they enter the differentiation pathways of megakaryocytes and erythrocytes respectively [21]. The differentiation of MEP into megakaryocytes and erythrocytes is affected by several key transcription factors, such as GATA binding protein 1 (GATA-1), friend of GATA-1 (FOG-1), Runt-related transcription factor 1 (RUNX1), etc. [22]. GATA-1 is a transcription factor that can initiate erythroid / megakaryocyte differentiation. When MEP cells are at the transition point of erythroid / megakaryocyte differentiation, GATA-1 is activated [23]. The selection of GATA-1 for the direction of cell differentiation is related to the active complex formed by GATA-1 and other regulatory proteins. GATA-1 interacts with the $\mathrm{N}$-terminal zinc finger structure of FOG-1 to activate the expression of erythroid related gene $\gamma$-globin and promote erythroid differentiation of cells [24]. On the contrary, GATA-1 forms a complex with RUNX1, which acts on the promoter GPIb $\alpha$ of megakaryocytes and promotes the differentiation of megakaryocytes, and the process of differentiation highly dependents on P-TEFb [25]. Thus, P-TEFb plays an important role in megakaryocyte/erythroid transition point and is the key regulatory molecule of directional differentiation. Inhibition of CDK9 kinase activity can inhibit the activity of $\mathrm{P}-\mathrm{TEFb}$, weaken the interaction between GATA-1 and RUNX1 protein, and inhibit megakaryocyte differentiation, thus promoting erythroid differentiation of cells.

Wogonin (5,7-dihydroxy-8-methoxy-2-phenyl4h-1-benzopyran-4-one) is one of the bioactive components isolated from the Chinese herbal medicine 
Scutellaria baicalensis, which has anti-oxidant, anticancer, anti-inflammatory and other pharmacological activities [26, 27]. Here, we investigated P-TEFb kinase activity in regulating differentiation in CML cells. Moreover, we verified that anti-proliferation activity of wogonin involved in $\mathrm{P}-\mathrm{TEFb}$ in vitro. Finally, we established a NOD/SCID mouse model bearing KU-812 tumors to further verify the anticancer effect and potential mechanism of wogonin.

\section{Materials and methods}

\section{Compounds and regents}

Wogonin (Purity $>99 \%$ ) was isolated from Scutellaria Baicalensis according to previously reported method [28]. Wogonin was dissolved in dimethyl sulfoxide (DMSO, Sigma-Aldrich, Missouri, USA) at a concentration of $0.1 \mathrm{M}$ and stored at $-80^{\circ} \mathrm{C}$. Then the solution was diluted to the indicated concentration with RPMI-1640 or IMDM medium (GIBCO, CarlsBAD, CA, USA). FITC anti-human CD71 (Transferrin Receptor), PE anti-human Glycophorin A (CD235a), FITC anti-human CD41 and $\mathrm{PE}$ anti-human CD61 antibodies were purchased from eBioscience (San Diego, CA, USA).

For in vivo experiments, wogonin was prepared as an intraperitoneal injection administration formulation by Dr. Xue Ke at the College of Pharmacy, China Pharmaceutical University. Imatinib Mesylate was purchased from CHIA TAI TIANQING PHARMACEUTICAL GROUP CO.LTD (Nanjing, China) and prepared as an intragastric administration.

\section{Cell cultures}

The chronic myeloid leukemia cell lines K562 and KU-812, human embryonic kidney cell line $293 \mathrm{~T}$ were purchased from the Cell Bank of the Shanghai Institute of Biochemistry \& Cell Biology. Primary chronic myeloid leukemia cells from newly diagnosed CML patients (The Affiliated DrumTower Hospital, Nanjing, China) were collected using lymphocyte-monocyte separation medium (Jingmei, Nanjing, China). K562 cells and primary CML cells were cultured in RPMI-1640 medium, KU-812 cells were cultured in IMDM medium, $293 \mathrm{~T}$ cells were cultured in DMEM medium, supplemented with $10 \%$ fetal bovine serum (FBS) (GIBCO, CarlsBAD, USA), $100 \mathrm{U} / \mathrm{ml}$ of benzylpenicillin and $100 \mathrm{U} / \mathrm{ml}$ of streptomycin in a humidified environment with $5 \% \mathrm{CO}_{2}$ at $37^{\circ} \mathrm{C}$.

\section{Flow cytometric analysis of apoptosis}

Annexin V/PI staining assay was used to detect apoptosis of cells after wogonin treatment. The cells were collected and stained with Annexin V/PI Cell Apoptosis Detection Kit (Vazyme biotec, Nanjing, China) according to the protocols. The fluorescence was detected by flow cytometry (Becton-Dickinson Biosciences, New Jersey, USA). and the data analysis was performed by Flowjo software.

\section{Flow cytometric analysis of cell differentiation}

K562 and KU-812 cells with different concentrations of wogonin were collected, the residual medium was washed with PBS, 0.5\% BSA solution was added and blown evenly. The non-specific binding sites on the surface of the two cells were sealed, centrifuged and washed with PBS to remove the residual BSA solution. After dispersing the cell mass with $50 \mu \mathrm{L}$ PBS, a certain amount of antibody was added to fully bind the fluorescently labeled antibody to the differentiated antigen on the CML cell surface. The antibody was incubated in a $37{ }^{\circ} \mathrm{C}$ shaker in darkness for $50 \mathrm{~min}$. Unbound antibody was washed with PBS and centrifuged. After resuspended with $400 \mu \mathrm{L}$ PBS, the positive cell percentage was analyzed and calculated using Flowjo program.

\section{Western blot analysis}

Total proteins were extracted from cells after wogonin treatments for indicated time. The cells were lysed in RIPA buffer (Thermo Scientific, Massachusetts, USA) with protease inhibitors (PMSF, NaF, leupeptin, and dithiothreitol) on ice for $50 \mathrm{~min}$ and then cell lysates were clarified by centrifugation at $14,000 \mathrm{rpm}$ (Eppendorf, Hamburg, Germany) for 20 min at $4{ }^{\circ} \mathrm{C}$. The concentration of proteins was quantified with a BCA Protein Assay Kit (Thermo Fisher Scientific, USA). Equal amounts of proteins were separated with $8-12 \%$ SDS-PAGE and transferred to the PVDF membranes (Millipore, Boston, MA, USA). Membranes were blocked with 3\% BSA and incubated overnight at $4{ }^{\circ} \mathrm{C}$ with primary antibodies, followed by incubation with HRP-coupled secondary antibody for $1 \mathrm{~h}$ at room temperature. After washing the membranes with PBST three times, detection was performed by AI600 imaging system (GE Healthcare, Pittsburgh, PA, USA).

Primary antibodies specific for RNA Pol II, p-RNA Pol II -Ser2, p-RNA Pol II -Ser5, MCL-1, Cyclin T1, FOG-1, GAPDH and $\beta$-actin were obtained from ABclonal Technology (Wuhan, China). Antibodies against CDK9, GATA-1 were obtained from Cell Signaling Technology (Danvers, MA). Antibody against RUNX1 was obtained from Proteintech (Wuhan, China). HRP Goat Anti-Rabbit IgG $(\mathrm{H}+\mathrm{L})$ and HRP Goat Anti-Mouse IgG $(\mathrm{H}+\mathrm{L})$ secondary antibody were obtained from ABclonal Technology (Wuhan, China).

\section{Immunoprecipitation}

Cell lysate was incubated with special antibody and 20 $\mu \mathrm{L}$ protein $\mathrm{A} / \mathrm{G}$-conjugated beads (MCE) at $4{ }^{\circ} \mathrm{C}$ overnight. After washing three times with PBS buffer, samples 
were collected and re-suspended in $20 \mu \mathrm{L}$ SDS-sample buffer $(0.5 \mathrm{M}$ Tris- $\mathrm{HCl}, \mathrm{pH} 6.8,20 \%$ glycerol, $2 \%$ SDS, $5 \%$ 2-mercaptoethanol and 4\%o bromophenol blue) and boiled for $10 \mathrm{~min}$. Then the samples were subjected to western blot with indicated antibodies.

\section{Cell transfection and lentivirus package}

For RNA interference by lentiviral vectors, $C D K 9$ shRNA constructs and a negative control construct created in the same vector system (pLKO.1) were purchased from Corues Biotechnology. Cells were co-transfected with shRNA constructs $(10 \mu \mathrm{g})$ together with Lentiviral Mix $(10 \mu \mathrm{L})$ and HG Transgene TM Reagent $(60 \mu \mathrm{L})$, according to the manufacturer's instruction of Lentiviral Packaging Kit (YEASEN). Viral supernatant was harvested from the culture medium $48 \mathrm{~h}$ after transfection. And then infected target cells with virus supernatant and selected $2 \mu \mathrm{g} / \mathrm{mL}$ puromycin for screening.

\section{Quantitative real-time RT-qPCR}

RT-qPCR was performed according to the manufacturer's instructions [29]. The primer sequences were as follows:

Human CDK9: forward: 5'- AAAGTCTGCCAG CTTCAGGA -3'.

reverse: 5' - ACTTCTGCGAGCATGACCTT -3'

Human GAPDH: forward: 5'TGATGACATCAAGAA GGTGGTGAA -3'.

reverse: 5' - TCCTTGGAGGCCATGTGGGCCAT -3'.

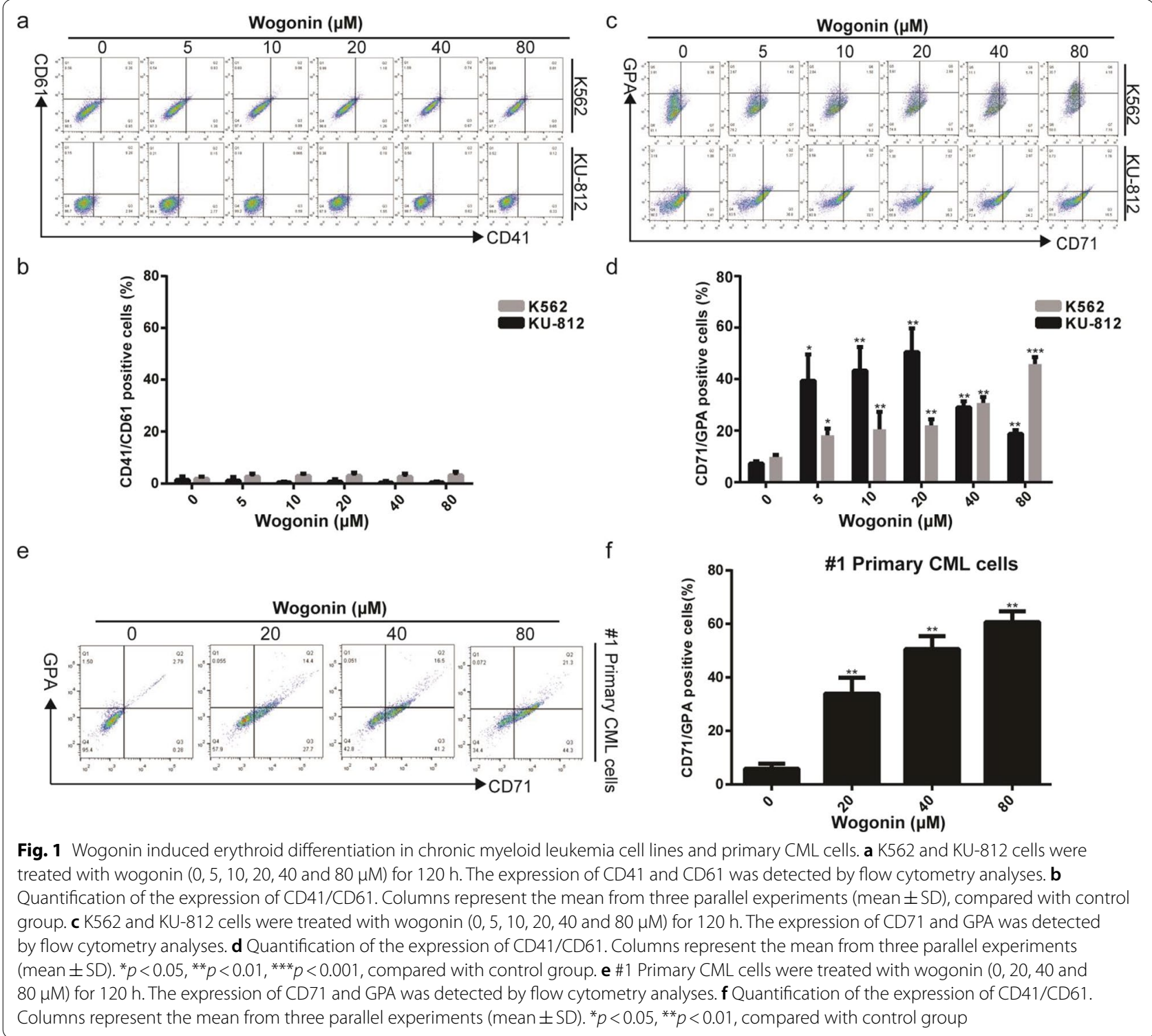




\section{Immunofluorescence analysis}

Immunofluorescence assays were performed as previously reported [30]. Images were observed with a confocal microscope (FV1000; Olympus, Tokyo, Japan).

\section{TUNEL assay}

Apoptosis was determined using a One Step TUNEL apoptosis assay kit (Beyotime, Jiangsu, China). A doublestaining technique was used; TUNEL staining (green fluorescence) was used to quantitate apoptotic cell nuclei and DAPI staining (blue fluorescence) was used to quantitate the total cell nuclei, as previously described [31]. The stained samples were observed under a confocal microscope (FV1000; Olympus, Tokyo, Japan). Three visual fields were selected randomly for each specimen.

\section{Animal models}

The female NOD/SCID mice (5 weeks old, weighing 16-20 g) (Cavens Changzhou Laboratory Animal Co., Ltd, Jiangsu, China) were sublethally irradiated (1.8 Gy) and were engrafted with KU-812 cells $\left(6 \times 10^{6}\right)$ via subcutaneously injection within $24 \mathrm{~h}$ following the radiation treatment. After 10 days, the mice were divided randomly into three groups ( $n=6$ per group): a control group ( $0.9 \%$ normal saline), a wogonin-treated group $(80 \mathrm{mg} / \mathrm{kg})$ and an Imatinib-treated group $(200 \mathrm{mg} / \mathrm{kg})$. The animals in wogonin groups were intraperitoneal injection (i.p) of wogonin $(80 \mathrm{mg} / \mathrm{kg}$, every day for 2 weeks). The animals in Imatinib-treated group were received administrated orally of Imatinib $(200 \mathrm{mg} / \mathrm{kg}$, every other day for 2 weeks). The tumor volume of mice was measured daily with an electronic vernier caliper. Finally, the animals were sacrificed, and the tumors were prepared for western blots and immunofluorescence assays, the spleens were prepared for flow cytometric analysis after the cells labeled with human CD45-PE (huCD45-PE) and the survival status are counted. The staining of huCD45-PE is used to determine the infiltration of KU-812 cells.

Animals were maintained in an air-conditioned and pathogen-free environment $\left(23 \pm 2{ }^{\circ} \mathrm{C}, 55 \pm 5 \%\right.$ humidity) under controlled lighting (12 h light/day) and supplied with standard laboratory food and water throughout the experimental period. The animal study was carried out according to the regulations of the China Food and Drug Administration (CFDA) on Animal Care.

\section{FACS analysis of cells extracted from spleens}

Cells extracted from spleens were performed as previously reported [32]. FACS Calibur flow cytometry was used to detect huCD45 positive cells. In this model, human CD45 positive cells were defined as human leukemia cells.

\section{Statistical analysis}

All results are expressed as the mean \pm SD from at least three independent experiments performed in a parallel manner. Statistical analyses of multiple group comparisons were performed by one-way analysis of variance followed by the Bonferroni post-hoc test. Comparisons between two groups were analyzed using two-tailed Student's $t$ tests. The significance of differences is indicated as ${ }^{*} p<0.05,{ }^{* * *} p<0.01$ and ${ }^{* * * *} p<0.001$.

\section{Result \\ Wogonin induced erythroid differentiation in chronic myeloid leukemia cell lines and primary CML cells}

In order to investigate anti-CML effects of wogonin, we first detect differentiation on K562, KU-812 and primary CML cells. K562 and KU-812 cells were treated with indicated concentrations of wogonin $(0,5,10,20,40$, $80 \mu \mathrm{M})$ for $120 \mathrm{~h}$. We examined the expression of CD41 and CD61, two megakaryocytic differentiation specific markers. However, the numbers of CD41 and CD61 positive cells did not have significant increased after wogonin treatment in K562 and KU-812 cells (Fig. 1a, b). We then detected the expression of CD71 and GPA, two erythroid differentiation specific markers. As shown in Fig. 1c, d, treatment with wogonin increased the proportion of CD71- and GPA-positive cells in K562 cells and KU-812 cells. In \#1 primary CML cells, wogonin induced erythroid differentiation in a concentration-dependent

\footnotetext{
(See figure on next page.)

Fig. 2 P-TEFb was involved in wogonin-induced erythroid differentiation and regulated the protein interaction of GATA-1, RUNX1 and FOG-1. a After treatment with wogonin $(0,5,10,20,40$ and $80 \mu \mathrm{M})$ for $48 \mathrm{~h}$ in $\mathrm{K} 562$ and $\mathrm{KU}-812$ cells, and in \# 1 primary CML cells wogonin $(0,20,40,80 \mu \mathrm{M})$ was treated for $48 \mathrm{~h}$. Protein expression levels of p-RNA Pol II (Ser2), p-RNA Pol II (Ser5), RNA Pol II and CDK9 were analyzed by western blot. $\beta$-actin was used as a loading control. The results are representative of three independent experiments(mean $\pm \mathrm{SD}) .{ }^{*} p<0.05,{ }^{* *} p<0.01,{ }^{* * *} p<0.001$, compared with control group. b After treatment with wogonin (0, 5, 10, 20, 40 and $80 \mu \mathrm{M})$ for $48 \mathrm{~h}$ in $\mathrm{K} 562$ and $\mathrm{KU}-812 \mathrm{cells}$, and in \# 1 primary CML cells wogonin $(0,20,40,80 \mu \mathrm{M})$ was treated for $48 \mathrm{~h}$. Protein expression levels of Cyclin T1 were analyzed by western blot. $\beta$-actin was used as a loading control. The results are representative of three independent experiments. (mean \pm SD). ${ }^{*} p<0.05,{ }^{* *} p<0.01$, compared with control group. c KU-812 cells were treated with wogonin $(0,5,10$ and $20 \mu \mathrm{M})$ for $72 \mathrm{~h}$. Cells were immunoprecipitated with anti-GATA-1 antibody, followed by western blot analysis with anti-FOG-1 and anti-RUNX1 antibodies. GAPDH and $\beta$-actin were used as a loading control respectively. The results are representative of three independent experiments (mean $\pm \mathrm{SD}$ ). ${ }^{*} p<0.05,{ }^{* *} p<0.01$, compared with control group
} 
a

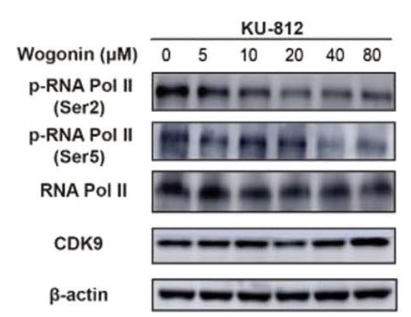

K562

RNAPoIII

CDK9

$\beta$-actin

p-RNA Pol II

(Ser5)

$\beta$-actin
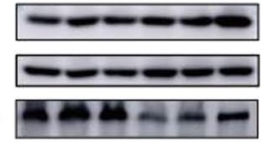

$-\infty-\infty$

\begin{tabular}{lllll} 
& \multicolumn{4}{c}{ \#1 Primary $\mathrm{CML}$ cells } \\
\cline { 2 - 4 } Wogonin $(\mu \mathrm{M})$ & 0 & 20 & 40 & 80 \\
& & & &
\end{tabular}

p-RNA Pol II
(Ser5)

RNA Pol II

$\beta$-actin

p-RNA Poll

(Ser2)

$\beta$-actin

CDK9

$\beta$-actin
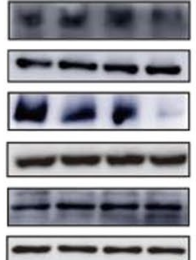

b
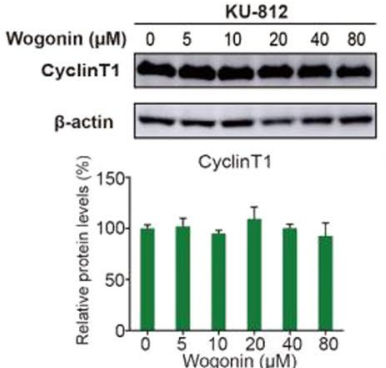
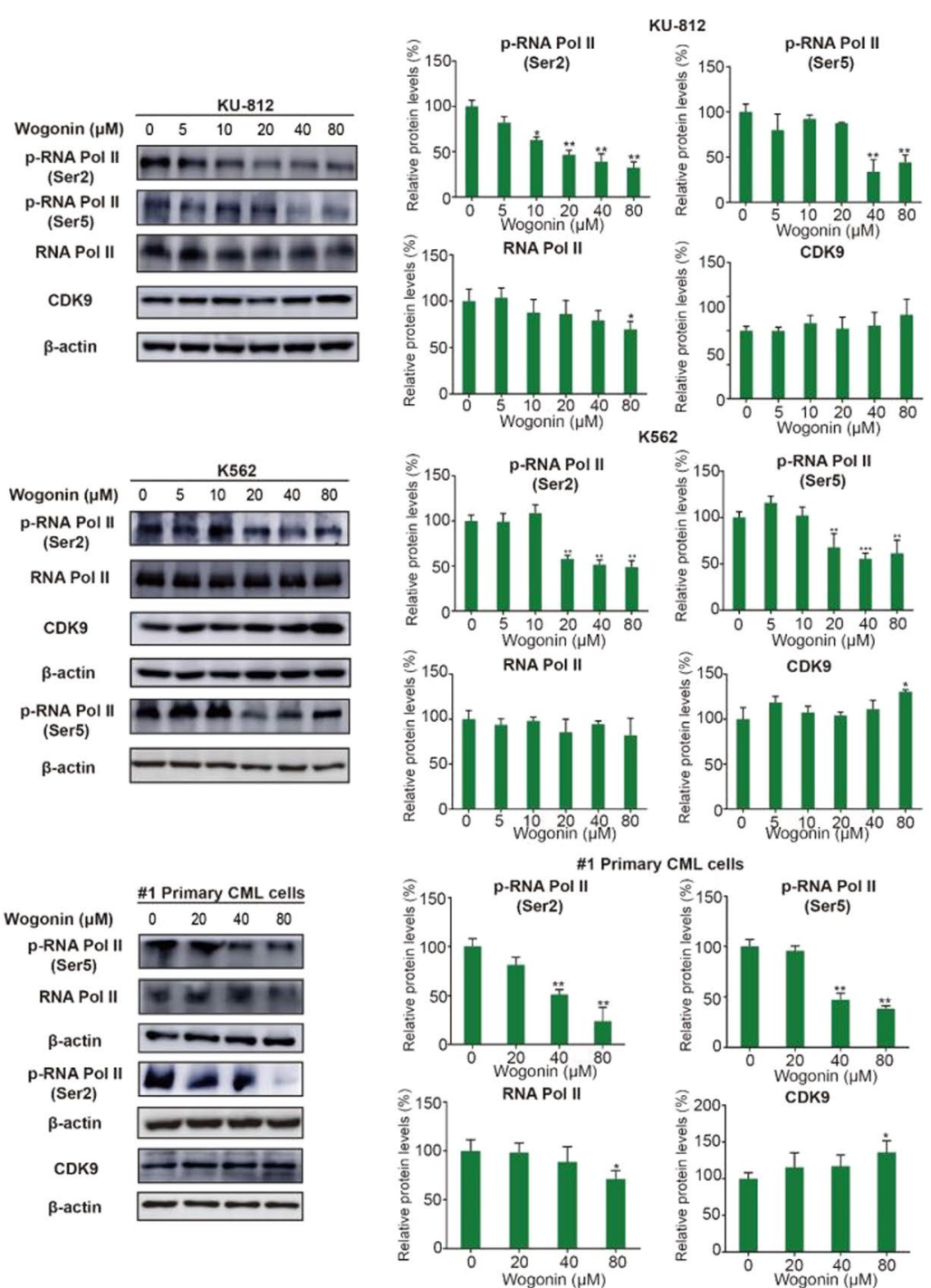

K562
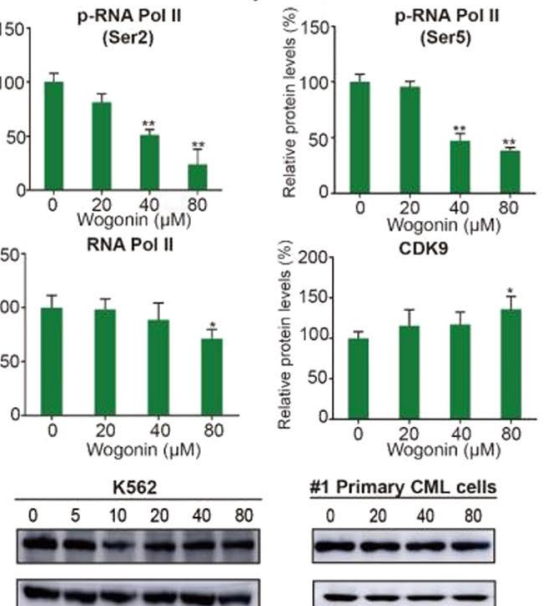

\#1 Primary CML cells

$\begin{array}{llll}0 & 20 & 40 & 80\end{array}$
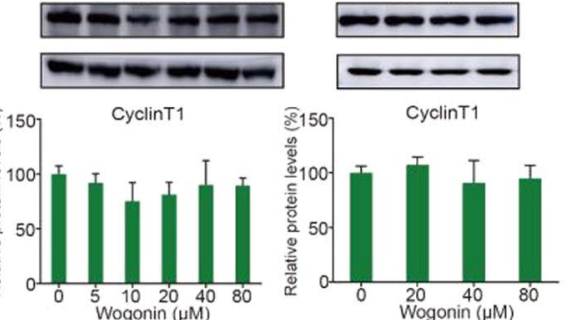

C
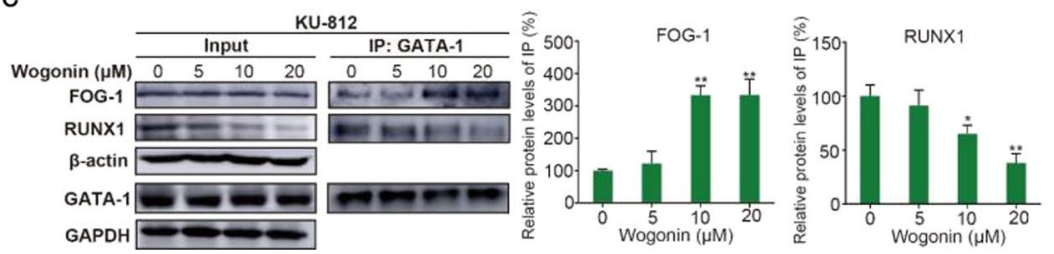

Fig. 2 (See legend on previous page.) 
manner (Fig. 1e, f). We concluded that wogonin induced erythroid differentiation but not megakaryocytic differentiation in K562, KU-812 and primary CML cells as judged by flow cytometry analyses.

\section{P-TEFb was involved in wogonin-induced erythroid differentiation and regulated the protein interaction of GATA-1, RUNX1 and FOG-1}

$\mathrm{P}-\mathrm{TEFb}$ is a general transcription factor that regulates transcription elongation through phosphorylation of the C-terminal tail domain (CTD) of RNA polymerase II (RNAP II), it is a heterodimer kinase composed of CDK9 and its regulated subunit Cyclin T1 [33]. For verifying whether erythroid differentiation associated with CDK9 on chronic myeloid leukemia cell lines and primary CML cells, we first constructed lentiviral recombinants expressing shRNA targeting CDK9 gene on K562 cells and evaluated knock down efficiency by using RTqPCR (Additional file 1: Fig. S1a). Then we also tested the expression of RNA Pol II, the phosphorylation level of RNA polymerase II (RNA Pol II Ser2 and Ser5) by western blot. Results showed that the expression of phosphorylation forms of RNA polymerase II Ser2 and Ser5 were both downregulated compared to negative control group, it was indicated that $\mathrm{P}-\mathrm{TEFb}$ kinase activity was inhibited when $C D K 9$ was knocked down (Additional file 1: Fig. S1b). To further confirm the involvement of $C D K 9$ on erythroid differentiation in CML cells, we detected the expression of surface antigens (CD71 and GPA) by flow cytometry analyses. Results showed that the ratio of erythroid differentiation was increased to $56.85 \pm 3.19 \%$ in shCDK9 group compared to negative control group (Additional file 1: Fig. S1c, d).

In previous studies we have already known wogonin is a CDK9 inhibitor, which directly binds to the ATP-binding pocket of CDK9 [34]. In order to investigate P-TEFb kinase activity involving in wogonin-induced erythroid differentiation, we examined the expression of the CTD of RNA Pol II in these cells. Western blot showed that the protein levels of RNA Pol II had slightly decreased and its phosphorylated forms (Ser2 and Ser5) were significantly decreased after treatment with various concentrations of wogonin $(0,5,10,20,40,80 \mu \mathrm{M})$ for $48 \mathrm{~h}$ in KU-812 cells (Fig. 2a). In K562 cells, the protein levels of RNA Pol II did not significantly change but its phosphorylated form (Ser2 and Ser5) were significantly decreased after treatment with various concentrations of wogonin for $48 \mathrm{~h}$ (Fig. 2a). The expression of CDK9 slightly increased after treatment of $80 \mu \mathrm{M}$ wogonin on $\mathrm{K} 562$ but in KU-812 cells the expression of CDK9 had no statistically significant difference (Fig. 2a). Similarly, in \#1 primary CML cells wogonin reduced the expression of RNA Pol II and its phosphorylation form (RNA Pol II Ser2 and Ser5), the level of CDK9 had slight increased by treatment with $80 \mu \mathrm{M}$ wogonin (Fig. 2a). Moreover, the expression of Cyclin T1 had no significant change in K562, KU-812 and \#1 primary CML cells (Fig. $2 b$ ). It is indicated that wogonin inhibited the kinase activity of P-TEFb by reducing the expression of the phosphorylation forms of RNA Pol II, which is a substrate protein of P-TEFb.

Some studies have shown that P-TEFb mediates the binding of GATA-1 and RUNX1, which promotes megakaryocytic differentiation and inhibits erythrocyte differentiation [35]. FOG-1 (Friend of GATA-1) specifically binds to the N-terminal zinc finger structure of GATA1, the protein interaction of GATA-1 and FOG-1 plays an essential role in erythrocyte differentiation [36]. Therefore, for further study the mechanism of wogonininduced erythroid differentiation, co-IP was used to investigate the protein interaction of GATA-1- FOG-1 and GATA-1-RUNX1 in KU-812 cells. As anticipated, wogonin increased the binding capacity of GATA-1 and FOG-1, however wogonin dramatically decreased the binding capacity of GATA-1 and RUNX1 (Fig. 2c).

\section{Wogonin induced apoptosis in KU-812 cells through downregulating MCL1}

To further investigate the effect of apoptosis in CML cells, Annexin V/PI double-staining assay was conducted in K562, KU-812 cells and \#1 primary CML cells treated by various concentrations of wogonin $(0,5,10,20,40$, $80 \mu \mathrm{M})$ for $48 \mathrm{~h}$. Results showed that high concentrations of wogonin $(40,80 \mu \mathrm{M})$ induced more obvious apoptosis in KU-812 cells, but did not in K562 and \#1 primary CML

\footnotetext{
(See figure on next page.)

Fig. 3 Wogonin induced apoptosis in KU-812 cells through downregulating MCL1. a KU-812, K562 and \#1 primary CML cells were treated with Wogonin $(0,5,10,20,40$ and $80 \mu \mathrm{M})$ for $48 \mathrm{~h}$. Flow cytometric analysis of Annexin V/PI stained cells. Data represent the mean \pm SD of three independent experiments. $\mathbf{b}$ Quantification of apoptosis cells. Columns represent the mean from three parallel experiments (mean $\pm S D)$. ${ }^{*} p<0.05$, ** $<<0.01$, compared with control group. c The mRNA level of MCL1 in KU-812, K562 cells and \#1 primary CML cells after cells were treated with wogonin $(0$ and $80 \mu \mathrm{M})$ for $48 \mathrm{~h}$. Columns represent the mean from three parallel experiments (mean $\pm \mathrm{SD}) .{ }^{* *} p<0.01$, compared with control group. $\mathbf{d}$ The protein expression level of MCL-1 in KU-812, K562 cells and \#1 primary CML cells after cells were treated with various concentrations of wogonin for $48 \mathrm{~h}$. $\beta$-actin and GAPDH was used as a loading control respectively. The results are representative of three independent experiments. e Quantification of the protein expression level of MCL-1 in KU-812, K562 cells and \#1 primary CML cells. Columns represent the mean from three parallel experiments (mean $\pm S D$ ). ${ }^{*} p<0.05,{ }^{* *} p<0.01$, compared with control group
} 


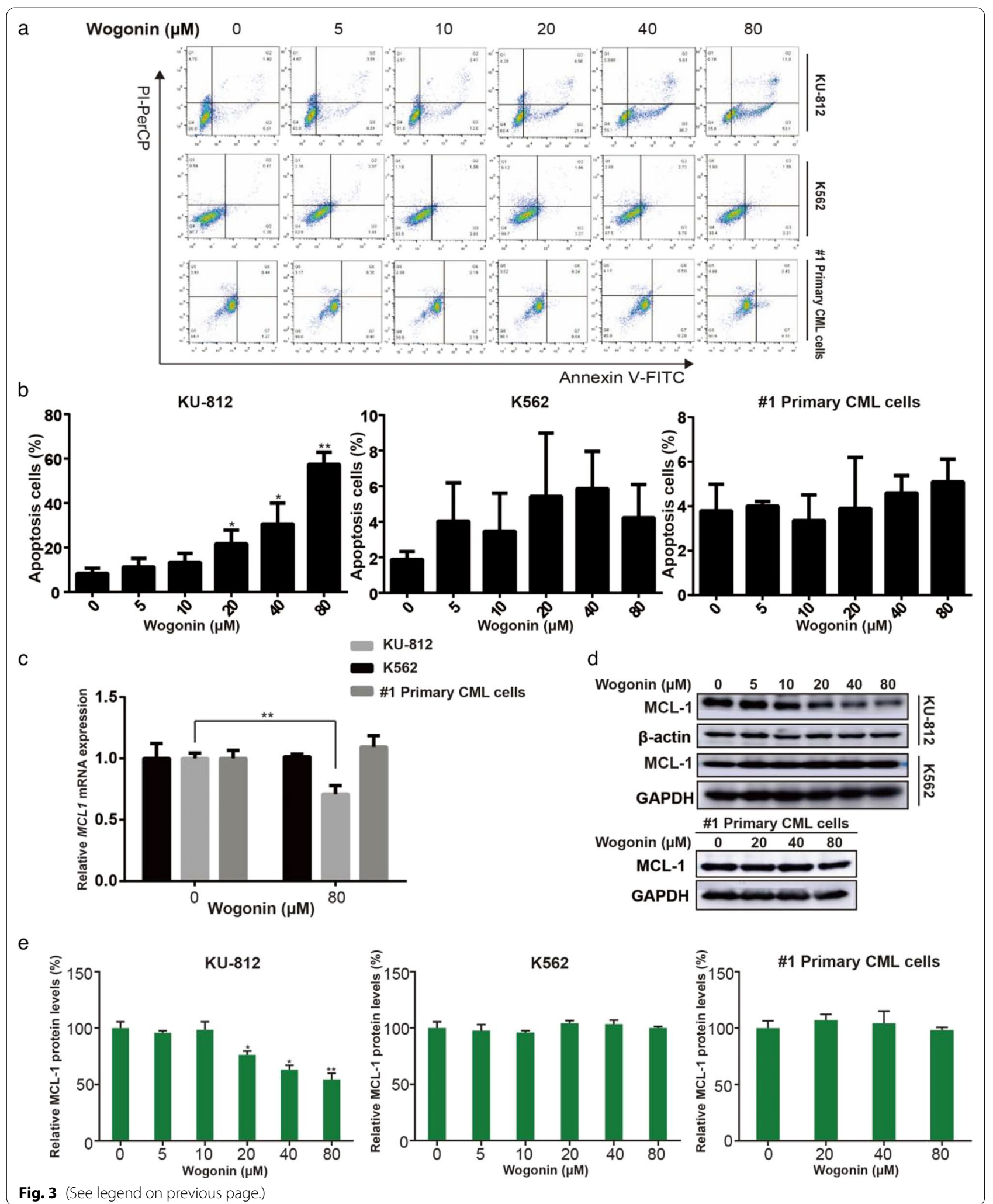


cells (Fig. 3a, b). Moreover, after treatment of wogonin $(80 \mu \mathrm{M})$ for $48 \mathrm{~h}$, KU-812 cells were dyed for TUNELFITC, compared with control group, wogonin treatment group was TUNEL-positive and the cells showed more green fluorescence, it was indicated that wogonin could induce apoptosis in KU-812 cells (Additional file 3: Fig. S3). Furthermore, as a downstream target gene of RNA Pol II, MCL1 is closely related the survival and maintenance of tumor cells [33]. In order to examine the mRNA level of $M C L 1$, we first used RT-PCR to detect the expression of MCL1 after treatment of wogonin. Results showed that $80 \mu \mathrm{M}$ wogonin inhibited transcriptional activity of MCL1 in KU-812 cells, but in K562 and primary CML cells no significant change was shown (Fig. 3c). Moreover, results of western blot showed that wogonin decreased the protein expression of MCL-1 in KU-812 cells in a concentration-dependent manner (Fig. 3d,e). Similar with the level of mRNA, wogonin had no effect on the protein expression of MCL-1 in K562 and \#1 prima ry CML cells (Fig. 3d, e). Therefore, the downregulation of $M C L 1$ would be the cause of wogonin-induced apoptosis in $\mathrm{KU}-812$ cells.

\section{Wogonin exhibited anti-CML effects and exerted lower toxicity in vivo}

In order to confirm wogonin-induced anti-CML effects in vivo, we constructed NOD/SCID mouse models engrafted with KU-812 cells via subcutaneous transplantation. The animals in control and wogonin-treated groups were intraperitoneal injection with solvent or wogonin $(80 \mathrm{mg} / \mathrm{kg}$, every day), and the animals in Imatinib-treated group were administrated orally $(200 \mathrm{mg} / \mathrm{kg}$, every other day). After administration for two weeks, we killed them and the graft tumors were taken out and weighed. As was indicated by tumor pattern, wogonin exhibited an observable tumor inhibition effect in KU-812 xenografts compared with the control group (Fig. 4a, b, c). Compared with Imatinib-treated group, the effect of wogonin-treated group was almost the same (Fig. 4a, b, c). The expression of Ki67 also indicated that both of wogonin and Imatinib possessed strong anti-proliferation activity (Fig. 4d). Moreover, the spleens of each group of mice were dissected and observed. Mice inoculated with KU-812 cells had significantly enlarged spleens, and splenomegaly was effectively alleviated in the treatment groups with wogonin and Imatinib (Fig. 4e, f). We also collected spleens randomly for biopsy which were selected from each group. Results of immunofluorescence showed that compared with mice in the blank group, the numbers of huCD $45^{+}$cells in spleens of mice inoculated with KU-812 cells were significantly increased in the control group, while the numbers of huCD $45^{+}$cells in wogonin and Imatinib-treated group were significantly decreased (Fig. 4g). For investigating whether wogonin had obvious toxicity on mice, we therefore assessed the effect of wogonin on animals' weight and main organs. As indicated in Additional file 2: Fig. S2a, there was a weight drop of mice in the Imatinib-treated group, while no significant weight loss was observed in wogonin group. According to hematoxylin and eosin staining of three organs from each mouse, we found that wogonin exerted lower toxicity whereas Imatinib-treated group displayed injuries of varying intensity (Additional file 2: Fig. S2b).

\section{Wogonin modulated P-TEFb kinase activity in vivo}

In order to verify the mechanism of wogonin-induced anti-CML activity in vivo, we detected P-TEFb kinase associated proteins in KU-812 transplanted tumors by western blot. Results showed that the expression of the phosphorylation forms of RNA polymerase II (p-RNA Pol II Ser2 and Ser5) and MCL-1 were decreased in wogonin-treated group compared to control group, which was consistent with the results in vitro (Fig. 5a). The expression of CDK9 and cyclin T1 did not have significant changes in wogonin-treated group (Fig. 5a). Moreover, immunofluorescence experiments also confirmed the decreased effect of wogonin on the expression of p-RNA Pol II (Ser2), p-RNA Pol II (Ser5) and MCL-1 in KU-812 cells xenografts (Fig. 5b).

For demonstrating erythroid differentiation induced by wogonin in vivo, we detected surface antigens CD71 and GPA in cells extracted from tumor issues of KU-812 cells-bearing NOD/SCID mice. Results showed that the GPA/CD71 positive ratio in wogonin-treated group

\footnotetext{
(See figure on next page.)

Fig. 4 Wogonin exhibits anti-tumor effects and exerted lower toxicity in vivo. In total, KU-812 cells $\left(6 \times 10^{6}\right.$ cells/mouse) were subcutaneously inoculated into NOD/SCID mice. The mice were randomized into 6 groups (6 mice per group), and treated with wogonin (80 mg/kg), Imatinib (200 mg/kg) and 0.9\% normal saline for 2 weeks. a The tumor volume was measured and calculated every other day. Data represent mean \pm SD of three independent experiments. ${ }^{*} p<0.05,{ }^{* *} p<0.01$, compared with control group. $\mathbf{b}$ The resulting tumors excised from the animals after treatment. c The tumor weights in three groups were compared. Quantification of the data shown. Data represent mean \pm SD of three independent experiments. ${ }^{*} p<0.05,{ }^{* *} p<0.01$, compared with control group. $\mathbf{d}$ Effect of wogonin on expression of Ki67 in KU-812 xenografts (Original magnification $\times 600$ ). $\mathbf{e}-\mathbf{f}$ Wogonin inhibits the splenomegaly of KU-812-bearing NOD/SCID mice. The typical photos of the spleen. Effect of wogonin on the weight of spleen in KU-812 cells-bearing NOD/SCID mice. Each data point represents the mean \pm SD of four animals for each group. ${ }^{* *} p<0.01,{ }^{* * *} p<0.001$, compared with control group. $\mathbf{g}$ Effect of wogonin on expression of huCD $45^{+}$in spleen of KU-812-bearing NOD/SCID mice. Spleen samples from three mice of each group (Original magnification $\times 600$ )
} 


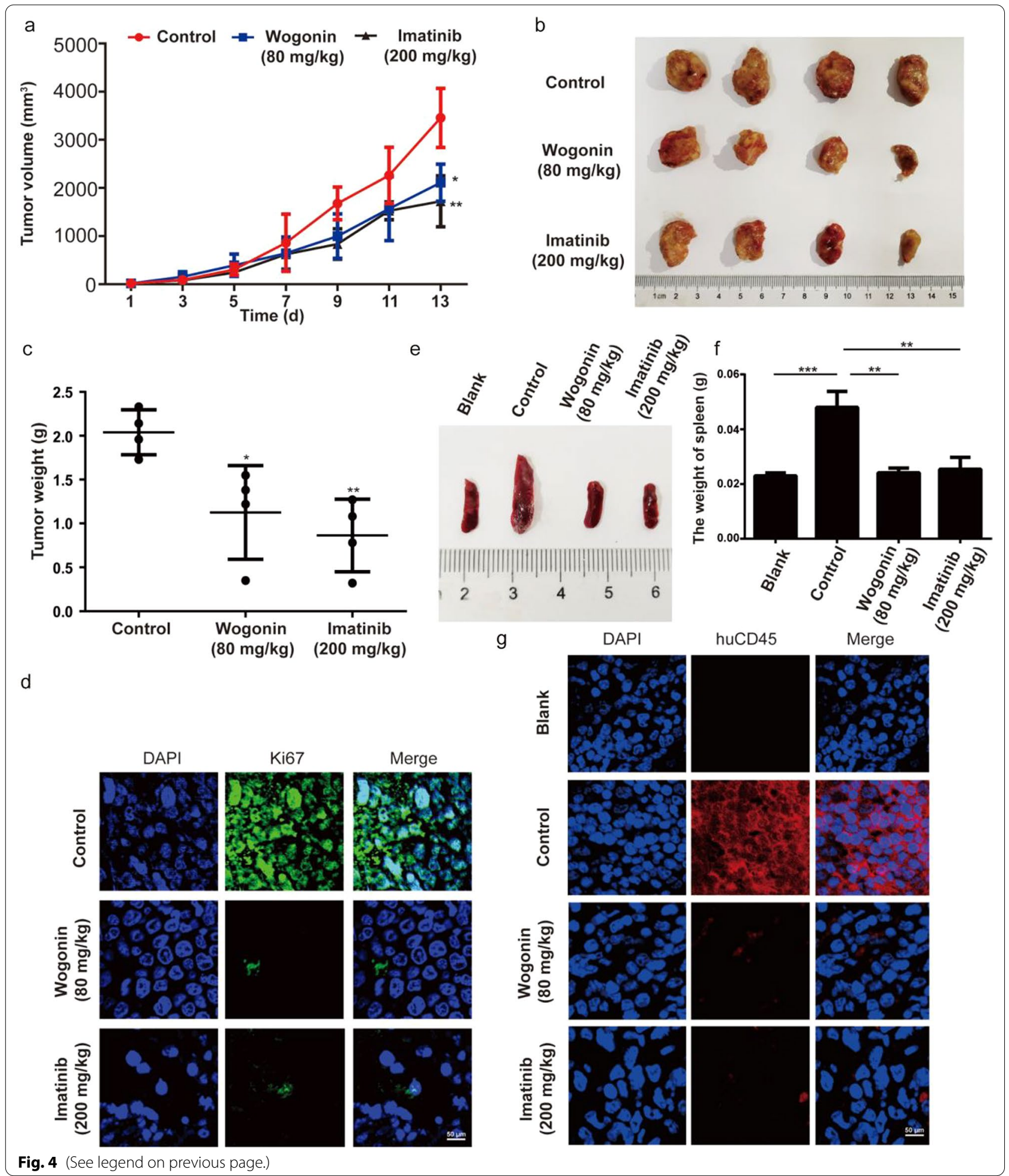

increased from $9.4 \pm 0.36 \%$ to $34.60 \pm 1.57 \%$ compared with control group, but in Imatinib-treated group no effect was observed (Fig. 5c, d). All these results indicated that wogonin could reduce the growth of CML cells by modulating P-TEFb kinase in vivo. 


\section{Discussion}

Although classic TKIs targeting BCR-ABL1 in CML cells makes patient's condition acquired greatly improved, but is not curative and frequently limited by intolerance or resistance [37]. Differentiation therapy remains a classical and unsurpassable therapeutic schedule in hematologic malignancies [38]. All-trans retinoic acid in treating acute promyelocytic leukemia (APL) results in cure rates of over $80 \%$ [39]. In this study, we found wogonin, a traditional flavonoid, induced differentiation and apoptosis in CML cells lines and primary CML cells mediated by P-TEFb. Moreover, wogonin inhibited the growth of KU-812 xenografts mediated by P-TEFb was also verified in vivo.

$\mathrm{P}-\mathrm{TEFb}$ complex is a special kinase that plays a key role in transcription elongation. RNA pol II is the main functional target of the complex. GATA-1, which is a key transcription factor that interacts with a variety of proteins including FOG-1 and RUNX1 to regulate erythroid and megakaryocyte differentiation respectively [35, 40]. However, FOG-1 negatively regulates RUNX1-GATA-1 cooperation, which attains the switch between erythroid and megakaryocyte differentiation [35]. The interaction of GATA-1 with RUNX1 is highly dependent on the $\mathrm{P}-\mathrm{TEFb}$ kinase complex $[22,35]$. It has been reported that wogonin induced erythroid differentiation in CML cells [41]. CDK9 is a core component of P-TEFb by binding with cyclinT1 to form an active P-TEFb kinase complex. Previous studies have shown that wogonin has a good inhibitory effect on CDK9 kinase [34]. To this end, we suspected that wogonin induced erythroid differentiation in CML cells involving modulation on P-TEFb.

GATA-1 is the key node of megakaryocyte / erythroid differentiation, and the formation of GATA-1/RUNX1 complex, which is necessary for megakaryocyte differentiation, depends on the activity of P-TEFb. However, whether inhibition of P-TEFb activity can promote erythroid differentiation remains unknown. Thus, we first used CDK9-shRNA to knock down the expression of CDK9 and results showed that erythroid differentiation was increased in CDK9-shRNA group compared to scramble group. Moreover, the expression of the downstream target of CDK9, the phosphorylated forms (Ser2 and
Ser5) of RNA pol II were also decreased in CDK9-shRNA group. It was indicated that P-TEFb kinase activity was associated with erythroid differentiation in CML cells. Then we found wogonin decreased the phosphorylated forms (Ser2 and Ser5) of RNA pol II in a concentrationdependent manner but did not change the expression of cyclin T1 in CML cell lines and primary CML cells. It was indicated that wogonin inhibited P-TEFb activity in CML cells. Moreover, co-immunoprecipitation assay showed that wogonin decreased the interaction of GATA-1 and RUNX1 but increased the interaction of GATA-1 and FOG-1. The results demonstrated that wogonin promoted erythroid differentiation but repressed megakaryocyte differentiation, which could attribute to the inhibition of P-TEFb activity. We also verified the inhibition of $\mathrm{P}-\mathrm{TEFb}$ activity in vivo, meanwhile, erythroid differentiation was also increased by wogonin in xenograft of KU-812 cells.

The transcription of protein with short half-lives like MCL-1 is prolonged via P-TEFb, which phosphorylates the carboxy terminal of RNA polymerase II [33, 42]. CDK9 is a critical component of P-TEFb. In this context, inhibition of CDK9 by wogonin blocked the activity of RNA pol II and induced apoptosis in KU-812 cells. As the downstream of RNA pol II, the transcriptional level of $M C L-1$ was decreased in KU-812 cells. Consistent with that the protein level of MCL-1 also decreased in KU-812 cells. Moreover, we verified the decreased expression of MCL-1 in in KU-812 cells xenografts. It's worth mention that the protein expression of MCL-1 was not significant decreased in vivo of Imatinib treated group (Fig. 5a, b). In general, some studies showed MCL-1 is a BCR-ABL dependent target in CML cells and TKIs could decreased the expression of MCL-1 [43]. However, heterogeneity of tumors in vivo study may cause abnormal expression of MCL-1 in Imatinib treated group. As a matter of fact, we found some studies showed MCL-1 expression elevated after Imatinib compared with control group in CML patients, which was linked to the drug resistance and individual difference [44].

In K562 and \#1 primary CML cells, wogonin could not induce apoptosis and decrease the expression of MCL1. We observed that in K562 cells wogonin-induced

(See figure on next page.)

Fig. 5 Wogonin modulated P-TEFb kinase activity in vivo. a The protein expression of p-RNA Pol II (Ser2), p-RNA Pol II (Ser5), CyclinT1, CDK9 and MCL-1 in KU-812 xenografts. $\beta$-actin was used as a loading control. The results are representative of three independent experiments (mean \pm SD). ${ }^{*} p<0.05,{ }^{* *} p<0.01$, compared with control group. b Immunofluorescence and stained with p-RNA Pol II (Ser2) (green fluorescence), p-RNA Pol II (Ser5) (green fluorescence) and MCL-1 (green fluorescence) respectively, as well as DAPI (blue fluorescence) in tumor of KU-812-bearing NOD/ SCID mice. They were detected by confocal microscopy (FV1000; Olympus) with FV10-ASW2.1 acquisition software (Olympus) at room temperature (Original magnification $\times 600$ ). c The expression of CD71 and GPA was detected in tumor of KU-812-bearing NOD/SCID mice by flow Cytometry analyses. d Quantification of the expression of CD71/GPA. Data represent mean \pm SD of three independent experiments. ${ }^{* *} p<0.001$, compared with control group 
a

Control

Wogonin $(80 \mathrm{mg} / \mathrm{kg})$

Imatinib $(200 \mathrm{mg} / \mathrm{kg})$

p-RNA Pol II
(Ser2)

p-RNA Pol II

(Ser5)

RNA Pol II

CDK9

MCL-1

Cyclin T1
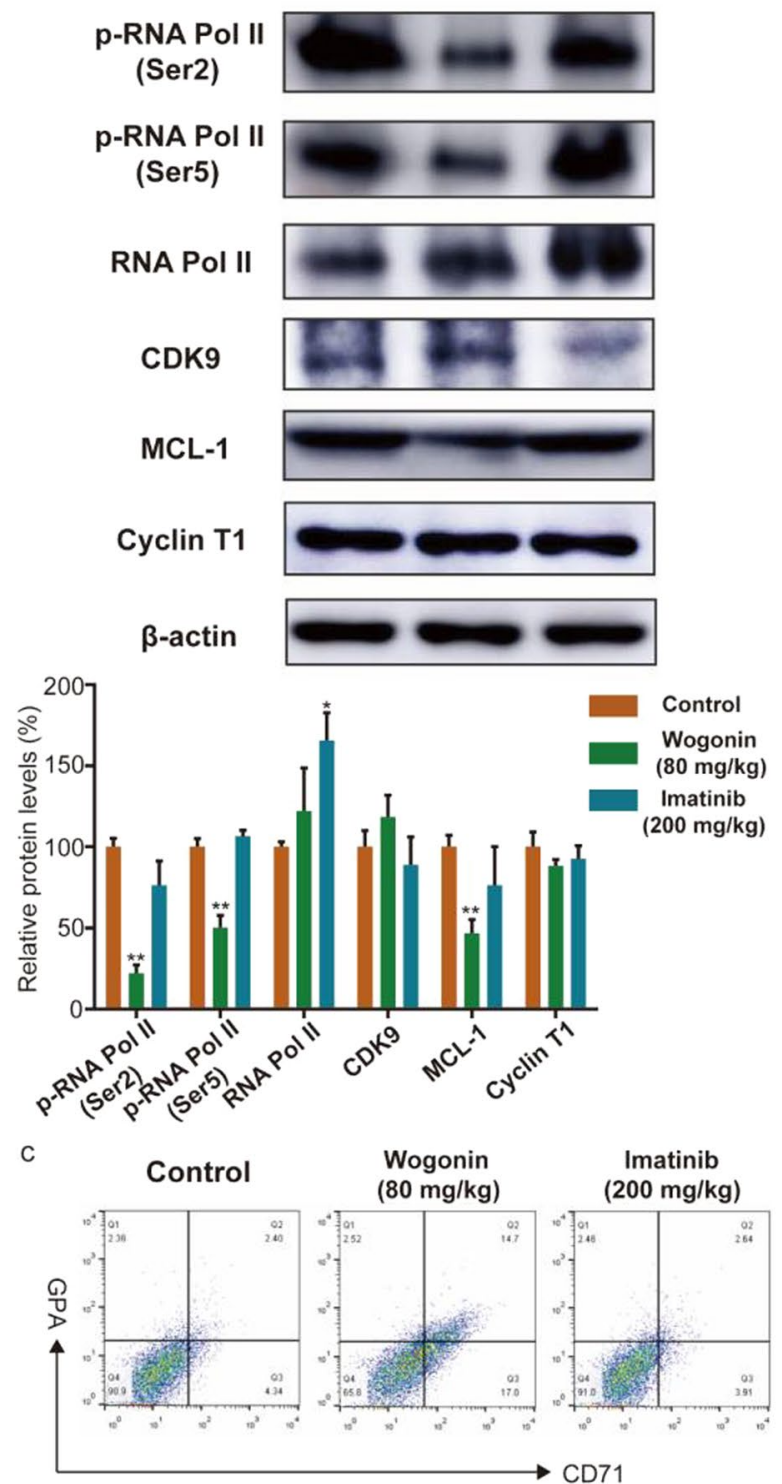

d

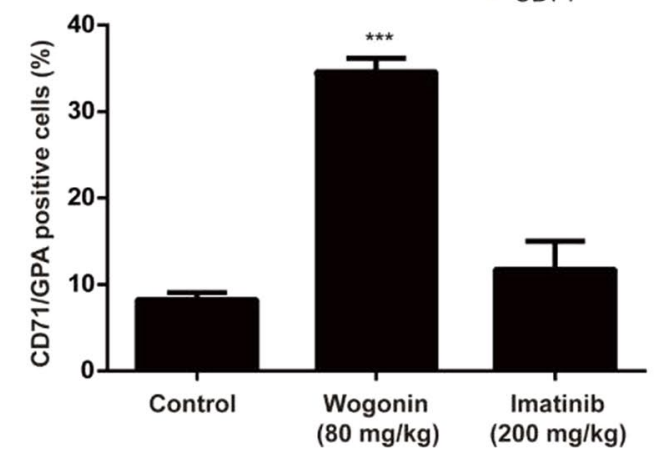

b
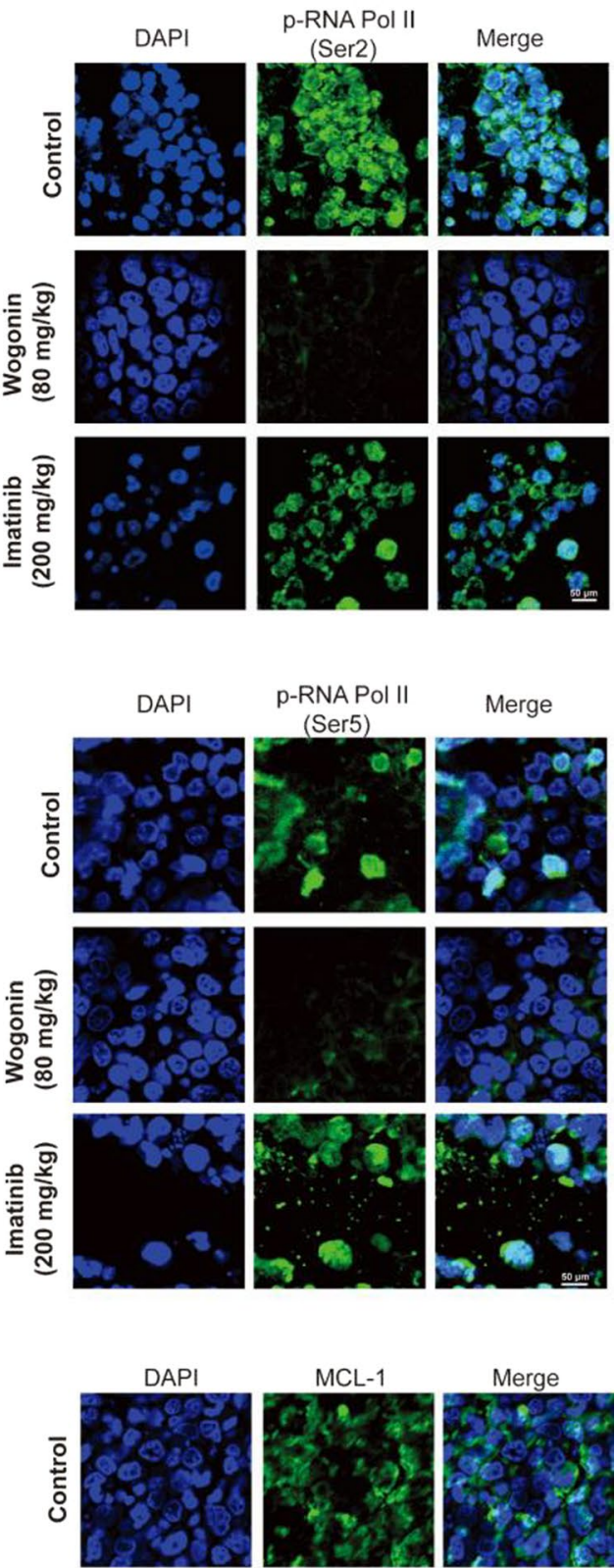

Merge
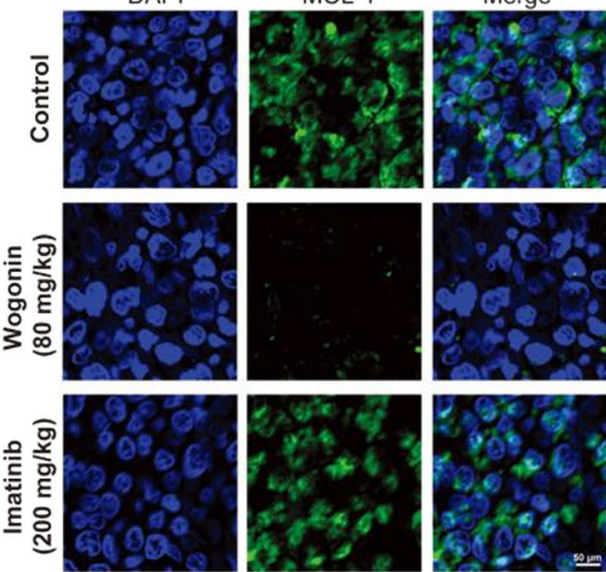

Fig. 5 (See legend on previous page.) 


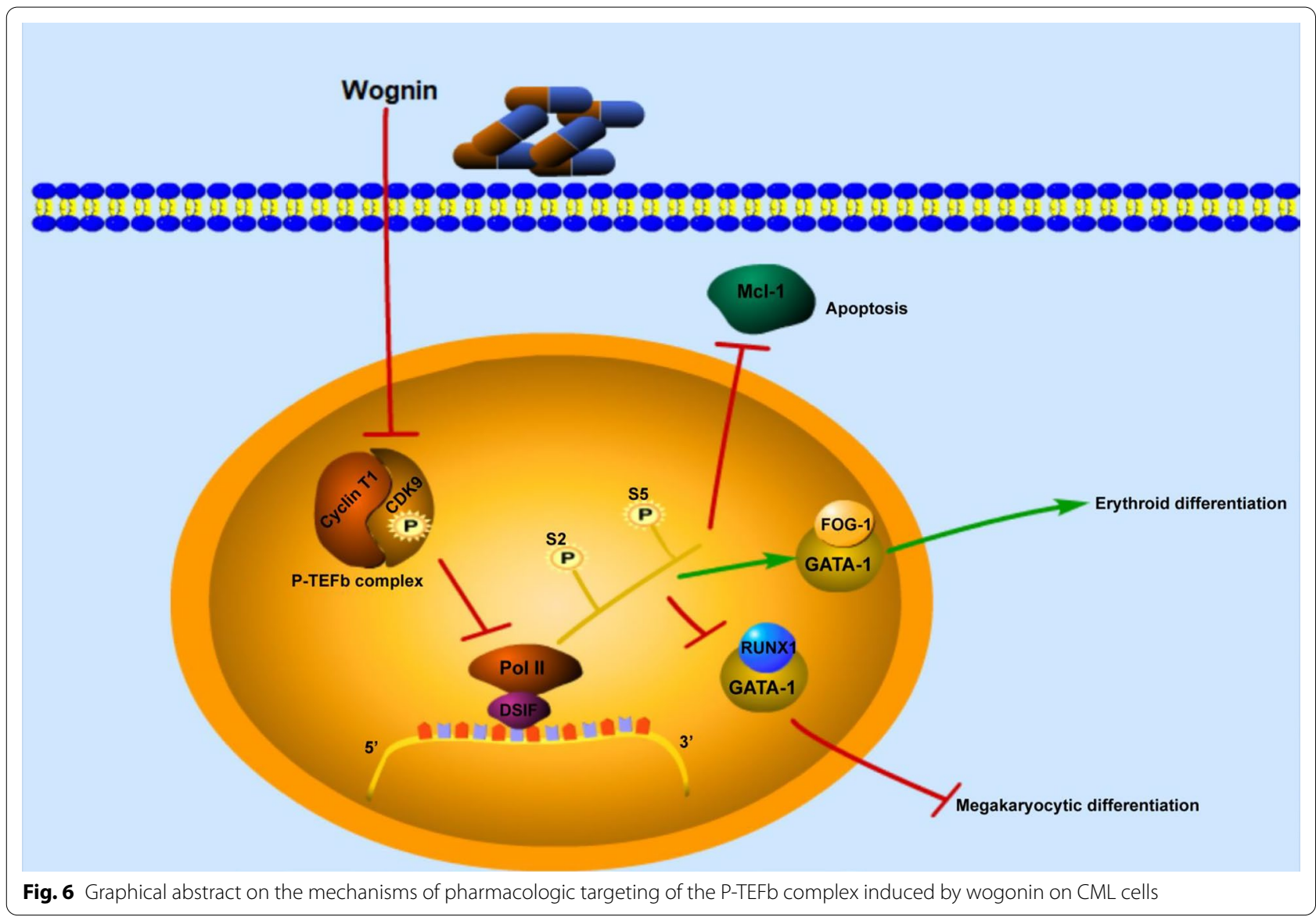

erythroid differentiation was concentration-dependent but in KU-812 cells, the degree of erythroid differentiation was gradually increased by the concentration of $0,5,10$, $20 \mu \mathrm{M}$ but decreased when the concentration was 40 and $80 \mu \mathrm{M}$. Although wogonin inhibited the kinase activity of $\mathrm{P}-\mathrm{TEFb}$ in CML cell lines and primary CML cells, MCL-1 is one of downstream target genes of RNA Pol II. As a matter of fact, a number of growth factors, cytokines and cytotoxic stimuli (e.g. drugs, radiation) regulate MCL-1 transcription through cell-type dependent effects on signal transduction pathways such as the PI3K/Akt, JAK/ STAT, p38/MAPK, and MEK/ERK pathways, with both antiapoptotic and proapoptotic stimuli involved [45, 46]. Thus not only RNA Pol II but also different types of signaling pathways may be involved in the regulation of MCL-1 expression, which depends on the cell types. In our study, we speculated that wogonin-induced different effects on MCL-1 may be regulated by different signaling pathways, which is not limited to RNA Pol II. Some studies showed that inhibiting apoptosis by ZVAD-fmk allows the surviving cells to differentiate towards the erythroid lineage, to some extent, BCR-ABL1-mediated apoptosis and erythroid differentiation are two independent processes which can be fully distinguished notably regarding their sensitivity to caspase and p38 MAP kinase inhibition. [47, 48]. It has been reported that overexpression of MCL1 may inhibit apoptosis and subsequent inhibition of apoptosis may support cellular cell differentiation of CML cells [49]. An investigation showed that one murine cell line, ELMI-1, required both activin A and EPO to achieve erythroid differentiation, however, apoptosis was induced by treatment with activin A alone. On the contrary, in another murine cell line, F5-5, differentiation was sufficiently induced by activin A alone to achieve an erythroid lineage. One possible explanation for these differences in activin A reactivity in these two cell lines was the state of the EPO receptor [50]. As observed in the case of wogonin in three types of cells, the differences among these cells like the state of the EPO receptor or cell sensitivity to wogonin may cause the different response degree in different cells, resulting in the transition of cell death and differentiation. The specific mechanism of the transformation of these two effects remains to be further explored.

Taken together, our results showed the involvement of $\mathrm{P}-\mathrm{TEFb}$ in wogonin-induced apoptosis and erythroid differentiation in CML cells. Furthermore, we demonstrated 
that wogonin induced-erythroid differentiation was associated with the increasing interaction of GATA-1 and FOG-1, which were regulated by P-TEFb. This research indicated that wogonin showed good inhibitory effect on CML cells through this unique mechanism, suggesting the potential application of wogonin in developing into a novel agent for the treatment of CML (Fig. 6).

\section{Conclusions}

Our research elucidated the regulatory mechanism of P-TEFb and GATA-1 signal crosslinking in the erythroid differentiation of CML cells induced by wogonin. Moreover, we demonstrated that wogonin induced erythroid differentiation of CML cells by inhibiting P-TEFb kinase activity, reducing the interaction between GATA-1 and RUNX-1, and promoting the binding of GATA- 1 to FOG1. This study highlighted a role of P-TEFb in wogonintreated CML cells and provided a potential mechanism for the application of wogonin.

\section{Abbreviations}

CML: Chronic myeloid leukemia; P-TEFb: The positive transcription elongation factor b; CDK9: Cyclin-dependent kinase 9; CDKs: Cyclin-dependent kinases; RNA Pol II: RNA Polymerase Il; CTD: C-Terminal Domain; APL: Acute promyelocytic leukemia; RA: Retinoic acid; CMP: Common myeloid progenitor; MEP: Megakaryocyte erythrocyte progenitor; GRA: Granulocyte macrophage progenitor; GATA-1: GATA binding protein 1; FOG-1: Friend of GATA-1; RUNX1: Runt-related transcription factor 1; RT-qPCR: Real-time quantitative polymerase chain reaction; TUNEL: TdT-mediated dUTP nick-end labeling; HSC: Hematopoietic stem cell.
\end{abstract}

\section{Supplementary Information}

The online version contains supplementary material available at https://doi. org/10.1186/s12964-021-00764-5.

Additional file 1. Figure S1. CDK9 shRNA K562 cells enhanced the rates of erythroid differentiation. (a) K562 cells were transfected with NC shRNA or CDK9 shRNA. The mRNA level of CDK9 was detected by RT-PCR. Data represent mean \pm SD of three independent experiments. ${ }^{* * *} p<0.001$, compared with control group. (b) In control, NC and shCDK9 groups, cell lysates were analysed for p-RNA Pol II (Ser2), p-RNA Pol II (Ser5), RNA Pol II and CDK9 expression by western Blot. Data represent mean \pm SD of three independent experiments. ${ }^{*} p<0.05,{ }^{* *} p<0.01$, compared with NC group. (c) In control, NC and shCDK9 groups, the expression of CD71 and GPA was detected by flow cytometry analyses. Data represent the mean \pm SD of three independent experiments. (d) Quantification of the expression of CD71/GPA. Data represent mean \pm SD of three independent experiments. ${ }^{* * *} p<0.001$, compared with NC group.

Additional file 2. Figure S2. Toxicological assessment. (a) NOD/SCID mice weights were recorded every 2 days. (b) H\&E stained main organs of mice from treated and control group to evaluate the toxicity of wogonin.

Additional file 3. Figure S3. Apoptosis detection of KU-812 cells by TUNEL (a) KU-812 cells were treated with wogonin $(0,80 \mu \mathrm{M})$ for $48 \mathrm{~h}$. Cell apoptosis was measured by TUNEL staining used a confocal microscope. Three visual fields were selected randomly for each specimen.

Acknowledgements

Thanks for all participants involved in this research.

\section{Authors' contributions}

YJQ and XYW designed and performed research, analyzed data, and wrote the paper; $\mathrm{HZW}$ and $\mathrm{PH}$ performed research and analyzed data; $\mathrm{HL}$ and XXY performed research; MYZ and ZYW collected data and performed statistical analysis; JYX provided the blood samples; YZ, JYX performed statistical analysis; and QLG and HH conceptualized the project and directed the experimental design data analysis. All authors read and approved the final manuscript.

\section{Funding}

The work was supported by the Nation Natural Science Foundation of China (81873046, 81830105, 81903647, 81503096, 81673461), the Drug Innovation Major Project (2017ZX09301014, 2018ZX09711001-003-007, 2017ZX09101003005-023), Natural Science Foundation of Jiangsu province (BK20190560, BE2018711), Nanjing Medical Science and Technology Development Project (YKK17074, YKK1 9064), Research and Innovation Project for College Graduates of Jiangsu Province (KYCX18_0803), China Postdoctoral Science Foundation (No. 2018M642373) and "Double First-Class" University project (CPU2018GF11, CPU2018GF05).

\section{Availability of data and materials}

The datasets supporting the conclusions of this article are included within the article and its additional files.

\section{Declarations}

\section{Ethical approval and consent to participate}

The animal study was carried out according to the regulations of the CFDA on Animal Care. All patients'samples were collected after informed consent in accordance with the Declaration of Helsinki. The study was approved by the Ethics Committee of China Pharmaceutical University.

\section{Consent for publication}

Not applicable.

\section{Competing interests}

Authors declare no conflicts of interest for this article.

\section{Author details}

${ }^{1}$ State Key Laboratory of Natural Medicines, Jiangsu Key Laboratory of Carcinogenesis and Intervention, China Pharmaceutical University, 24 Tongjiaxiang, Nanjing 210009, People's Republic of China. ${ }^{2}$ Department of Pharmacology, School of Medicine and Holostic Integrative Medicine, Nanjing University of Chinese Medicine, Nanjing 210023, People's Republic of China. ${ }^{3}$ Department of Hematology, The First Affiliated Hospital of Nanjing Medical University, Jiangsu Province Hospital, Nanjing 210029, People's Republic of China. ${ }^{4}$ Department of Hematology, The Affiliated DrumTower Hospital of Nanjing University Medical School, Nanjing 210008, People's Republic of China.

Received: 3 March 2021 Accepted: 2 July 2021

Published online: 09 August 2021

\section{References}

1. Horne GA, Stobo J, Kelly C, Mukhopadhyay A, Latif AL, Dixon-Hughes J, McMahon L, Cony-Makhoul P, Byrne J, Smith G, et al. A randomised phase II trial of hydroxychloroquine and imatinib versus imatinib alone for patients with chronic myeloid leukaemia in major cytogenetic response with residual disease. Leukemia. 2020;34:1775-86.

2. Abduelkarem AR, Anbar HS, Zaraei SO, Alfar AA, Al-Zoubi OS, Abdelkarem EG, El-Gamal MI. Diarylamides in anticancer drug discovery: A review of pre-clinical and clinical investigations. Eur J Med Chem. 2020 Feb 15;188:112029.

3. Kantarjian HM, O'Brien S, Anderlini P, Talpaz M. Treatment of myelogenous leukemia: current status and investigational options. Blood. 1996;87:3069-81.

4. Karvela M, Baquero P, Kuntz EM, Mukhopadhyay A, Mitchell R, Allan EK, Chan E, Kranc KR, Calabretta B, Salomoni P, et al. ATG7 regulates energy metabolism, differentiation and survival of Philadelphia-chromosomepositive cells. Autophagy. 2016;12:936-48. 
5. Craddock CF. We do still transplant CML, don't we? Hematology Am Soc Hematol Educ Program. 2018;2018:177-84.

6. Bhatia R. Novel approaches to therapy in CML. Hematology Am Soc Hematol Educ Program. 2017;2017:115-20.

7. Mauro MJ. Novel tyrosine kinase inhibitors for patients with inadequate response in chronic myeloid leukemia. Curr Opin Hematol. 2019;26:119-23.

8. Tibes R, McDonagh KT, Lekakis L, Bogenberger JM, Kim S, Frazer N, Mohrland S, Bassett D, Garcia R, Schroeder K, et al. Phase I study of the novel Cdc2/CDK1 and AKT inhibitor terameprocol in patients with advanced leukemias. Invest New Drugs. 2015;33:389-96.

9. Laitem C, Zaborowska J, Isa NF, Kufs J, Dienstbier M, Murphy S. CDK9 inhibitors define elongation checkpoints at both ends of RNA polymerase Il-transcribed genes. Nat Struct Mol Biol. 2015;22:396-403.

10. Shapiro Gl. Cyclin-dependent kinase pathways as targets for cancer treatment. J Clin Oncol. 2006;24:1770-83.

11. Tellier M, Hardy JG, Norbury CJ, Murphy S. Effect of CFIm 25 knockout on RNA polymerase II transcription. BMC Res Notes. 2018;11:894.

12. Fant CB, Levandowski CB, Gupta K, Maas ZL, Moir J, Rubin JD, Sawyer A, Esbin MN, Rimel JK, Luyties O, et al. TFIID enables RNA polymerase II promoter-proximal pausing. Mol Cell. 2020;78:785-93.

13. Schier AC, Taatjes DJ. Structure and mechanism of the RNA polymerase II transcription machinery. Genes Dev. 2020;34:465-88.

14. Booth GT, Parua PK, Sansó M, Fisher RP, Lis JT. Cdk9 regulates a promoterproximal checkpoint to modulate RNA polymerase II elongation rate in fission yeast. Nat Commun. 2018;9:543.

15. Morales F, Giordano A. Overview of CDK9 as a target in cancer research. Cell Cycle. 2016;15:519-27.

16. Bowman EA, Kelly WG. RNA polymerase II transcription elongation and Pol II CTD Ser2 phosphorylation: a tail of two kinases. Nucleus. 2014:5:224-36.

17. Bacon CW, D'Orso I. CDK9: a signaling hub for transcriptional control. Transcription. 2019:10:57-75.

18. Olson CM, Jiang B, Erb MA, Liang Y, Doctor ZM, Zhang Z, Zhang T, Kwiatkowski N, Boukhali M, Green JL, et al. Pharmacological perturbation of CDK9 using selective CDK9 inhibition or degradation. Nat Chem Biol. 2018;14:163-70.

19. Sell S, Nicolini A, Ferrari P, Biava PM. Cancer: a problem of developmental biology; scientific evidence for reprogramming and differentiation therapy. Curr Drug Targets. 2016;17:1103-10.

20. de Thé H. Differentiation therapy revisited. Nat Rev Cancer. 2018:18:117-27.

21. Dzierzak E, Philipsen S. Erythropoiesis: development and differentiation. Cold Spring Harb Perspect Med. 2013 Apr 1:3(4):a011601.

22. Elagib KE, Mihaylov IS, Delehanty LL, Bullock GC, Ouma KD, Caronia JF, Gonias SL, Goldfarb AN. Cross-talk of GATA-1 and P-TEFb in megakaryocyte differentiation. Blood. 2008;1 12:4884-94.

23. Gutiérrez L, Caballero N, Fernández-Calleja L, Karkoulia E, Strouboulis J. Regulation of GATA1 levels in erythropoiesis. IUBMB Life. 2020;72:89-105.

24. Szulawska A, Arkusinska J, Czyz M. Accumulation of gamma-globin mRNA and induction of irreversible erythroid differentiation after treatment of CML cell line K562 with new doxorubicin derivatives. Biochem Pharmacol. 2007:73:175-84.

25. Xu G, Kanezaki R, Toki T, Watanabe S, Takahashi Y, Terui K, Kitabayashi I, Ito E. Physical association of the patient-specific GATA1 mutants with RUNX1 in acute megakaryoblastic leukemia accompanying Down syndrome. Leukemia. 2006;20:1002-8.

26. Wang J, Li T, Zhao T, Wu T, Liu C, Ding H, Li Z, Bian J. Design of wogonininspired selective cyclin-dependent kinase 9 (CDK9) inhibitors with potent in vitro and in vivo antitumor activity. Eur J Med Chem. 2019;178:782-801.

27. Huynh DL, Sharma N, Kumar Singh A, Singh Sodhi S, Zhang JJ, Mongre RK, Ghosh M, Kim N, Ho Park Y, Kee Jeong D. Anti-tumor activity of wogonin, an extract from Scutellaria baicalensis, through regulating different signaling pathways. Chin J Nat Med. 2017;15:15-40.

28. Hui KM, Huen MS, Wang HY, Zheng H, Sigel E, Baur R, Ren H, Li ZW, Wong $J T$, Xue H. Anxiolytic effect of wogonin, a benzodiazepine receptor ligand isolated from Scutellaria baicalensis Georgi. Biochem Pharmacol. 2002;64:1415-24

29. Chen Y, Hui H, Yang H, Zhao K, Qin Y, Gu C, Wang X, Lu N, Guo Q. Wogonoside induces cell cycle arrest and differentiation by affecting expression and subcellular localization of PLSCR1 in AML cells. Blood. 2013;121:3682-91.

30. Li H, Yu X, Liu X, Hu P, Shen L, Zhou Y, Zhu Y, Li Z, Hui H, Guo Q, Xu J. Wogonoside induces depalmitoylation and translocation of PLSCR1 and N-RAS in primary acute myeloid leukaemia cells. J Cell Mol Med. 2018;22:2117-30

31. Li ZL, Hu J, Li YL, Xue F, Zhang L, Xie JQ, Liu ZH, Li H, Yi DH, Liu JC, Wang $\mathrm{SW}$. The effect of hyperoside on the functional recovery of the ischemic/ reperfused isolated rat heart: potential involvement of the extracellular signal-regulated kinase 1/2 signaling pathway. Free Radic Biol Med. 2013;57:132-40.

32. Hu P, Li H, Yu X, Liu X, Wang X, Qing Y, Wang Z, Wang H, Zhu M, Xu J, et al. GL-V9 exerts anti-T cell malignancies effects via promoting lysosomedependent AKT1 degradation and activating AKT1/FOXO3A/BIM axis. Free Radic Biol Med. 2019;145:237-49.

33. Phillips DC, Jin S, Gregory GP, Zhang Q, Xue J, Zhao X, Chen J, Tong Y, Zhang $\mathrm{H}$, Smith M, et al. A novel CDK9 inhibitor increases the efficacy of venetoclax (ABT-199) in multiple models of hematologic malignancies. Leukemia. 2020;34:1646-57.

34. Polier G, Ding J, Konkimalla BV, Eick D, Ribeiro N, Köhler R, Giaisi M, Efferth T, Desaubry L, Krammer PH, Li-Weber M: Wogonin and related natural flavones are inhibitors of CDK9 that induce apoptosis in cancer cells by transcriptional suppression of Mcl-1. Cell Death Dis 2011, 2(7):e182.

35. Goldfarb AN. Megakaryocytic programming by a transcriptional regulatory loop: a circle connecting RUNX1, GATA-1, and P-TEFb. J Cell Biochem. 2009; 107:377-82.

36. Nogueira-Pedro A, dos Santos GG, Oliveira DC, Hastreiter AA, Fock RA. Erythropoiesis in vertebrates: from ontogeny to clinical relevance. Front Biosci (Elite Ed). 2016;8:100-12.

37. Westerweel PE, Te Boekhorst PAW, Levin MD, Cornelissen JJ. New approaches and treatment combinations for the management of chronic myeloid leukemia. Front Oncol. 2019;9:665.

38. Pan P, Chen X. Nuclear Receptors as Potential Therapeutic Targets for Myeloid Leukemia. Cells. 2020 Aug 19;9(9):1921.

39. Christian S, Merz C, Evans L, Gradl S, Seidel H, Friberg A, Eheim A, Lejeune P, Brzezinka K, Zimmermann K, et al. The novel dihydroorotate dehydrogenase (DHODH) inhibitor BAY 2402234 triggers differentiation and is effective in the treatment of myeloid malignancies. Leukemia. 2019;33:2403-15

40. Cantor AB, Orkin SH. Coregulation of GATA factors by the Friend of GATA (FOG) family of multitype zinc finger proteins. Semin Cell Dev Biol. 2005:16:117-28.

41. Yang H, Hui H, Wang Q, Li H, Zhao K, Zhou Y, Zhu Y, Wang X, You Q, Guo Q, Lu N. Wogonin induces cell cycle arrest and erythroid differentiation in imatinib-resistant $\mathrm{K} 562$ cells and primary CML cells. Oncotarget. 2014:5:8188-201.

42. Kinoshita S, Ishida T, Ito A, Narita T, Masaki A, Suzuki S, Yoshida T, Ri M, Kusumoto S, Komatsu H, et al. Cyclin-dependent kinase 9 as a potential specific molecular target in NK-cell leukemia/lymphoma. Haematologica. 2018;103:2059-68.

43. Aichberger KJ, Mayerhofer M, Krauth MT, Skvara H, Florian S, Sonneck K, Akgul C, Derdak S, Pickl WF, WacheckV, et al. Identification of mcl-1 as a $\mathrm{BCR} / \mathrm{ABL}$-dependent target in chronic myeloid leukemia (CML): evidence for cooperative antileukemic effects of imatinib and $\mathrm{mcl}-1$ antisense oligonucleotides. Blood. 2005;105:3303-11.

44. Ferreira AF, de Oliveira GL, Tognon R, Collassanti MD, Zanichelli MA, Hamerschlak N, de Souza AM, Covas DT, Kashima S, de Castro FA. Apoptosis-related gene expression profile in chronic myeloid leukemia patients after imatinib mesylate and dasatinib therapy. Acta Haematol. 2015:133:354-64

45. Wei AH, Roberts AW, Spencer A, Rosenberg AS, Siegel D, Walter RB, Caenepeel S, Hughes P, Mclver Z, Mezzi K, et al: Targeting MCL-1 in hematologic malignancies: Rationale and progress. Blood Rev 2020, 44:100672.

46. Le Gouill S, Podar K, Harousseau JL, Anderson KC. Mcl-1 regulation and its role in multiple myeloma. Cell Cycle. 2004;3:1259-62.

47. Jacquel A, Colosetti P, Grosso S, Belhacene N, Puissant A, Marchetti S, Breittmayer JP, Auberger P. Apoptosis and erythroid differentiation triggered by Bcr-Abl inhibitors in CML cell lines are fully distinguishable processes that exhibit different sensitivity to caspase inhibition. Oncogene. 2007:26:2445-58. 
48. Krauss SW, Lo AJ, Short SA, Koury MJ, Mohandas N, Chasis JA. Nuclear substructure reorganization during late-stage erythropoiesis is selective and does not involve caspase cleavage of major nuclear substructural proteins. Blood. 2005;106:2200-5.

49. Fukuchi Y, Kizaki M, Yamato K, Kawamura C, Umezawa A, Hata J, Nishihara T, Ikeda Y. Mcl-1, an early-induction molecule, modulates activin A-induced apoptosis and differentiation of CML cells. Oncogene. 2001;20:704-13.
50. Shiozaki M, Kosaka M, Eto Y. Activin A: a commitment factor in erythroid differentiation. Biochem Biophys Res Commun. 1998;242:631-5.

\section{Publisher's Note}

Springer Nature remains neutral with regard to jurisdictional claims in published maps and institutional affiliations.
Ready to submit your research? Choose BMC and benefit from:

- fast, convenient online submission

- thorough peer review by experienced researchers in your field

- rapid publication on acceptance

- support for research data, including large and complex data types

- gold Open Access which fosters wider collaboration and increased citations

- maximum visibility for your research: over $100 \mathrm{M}$ website views per year

At BMC, research is always in progress.

Learn more biomedcentral.com/submissions 